\title{
PENDEKATAN KOMUNIKASI INTERNASIONAL
}

\author{
Deddy Djamaluddin Malik
}

Sekolah Tinggi Ilmu Komunikasi Bandung, Jl. Soekarno Hatta No.3, Binong, Batununggal, Kota Bandung, Jawa Barat 40275

dedy_malik@yahoo.com

\begin{abstract}
This article purpose is discribe historical setting, approach, definition and scope of international communication. The coming of globalization makes change some activities and orientations in this field. The method used in this article is literature study related to international communication, global communication and international relations. The result of this study that the term of international communication is altered by term of global communication. But in academic environment, the old term still its used. Second, there is many approach to international communication. The last one, the writer explore the position and function of international communication.
\end{abstract}

Keyword: public diplomacy, propaganda, soft power

\begin{abstract}
Abstrak
Artikel ini bertujuan untuk menggambarkan latar belakang sejarah, pendekatan, definisi dan ruang lingkup komunikasi internasional. Kedatangan globalisasi membuat perubahan beberapa aktivitas dan orientasi di bidang ini. metode yang digunakan dalam artikel ini adalah studi pustaka terkait komunikasi internasional, komunikasi global dan hubungan internasional. Hasil penelitian ini bahwa istilah komunikasi internasional diubah oleh istilah komunikasi global. Tapi di lingkungan akademik, istilah lama tetap digunakan. Kedua, ada banyak pendekatan terhadap komunikasi internasional. Yang terakhir, penulis mengeksplorasi posisi dan fungsi komunikasi internasional.
\end{abstract}

Kata kunci : Diplomasi publik, propaganda, soft power 


\section{Sejarah K omunikasi Internasional}

"Sejarah komunikasi internasional dan pertukaran budaya" kata Kamalipour, dalam Global Communication (2002:viii), "sama tuanya dengan peradaban manusia". Masyarakat beradab yang tidak pernah dipengaruhi oleh kebudayaan lain, tak akan pernah ada. Pada masa kuno atau abad pertengahan saling mempengaruhi peradaban adalah sesuatu yang lumrah. Tidak ada seorang pun yang mengeluhkannya. Tetapi belakangan, tepatnya sejak abad ke-19 pengaruh kebudayaan asing mulai menjadi masalah karena dua alasan kata Kamalipour. Pertama, batas dan skala pengaruh kebudayaan asing meningkat signifikan. Kedua, bangkitnya nasionalisme di banyak kawasan negeri telah mempengaruhi cara pandang orang terhadap kebudayaan asing.

Lahirnya komunikasi internasional di Amerika, Inggris, dan hampir di seluruh kawasan Eropa adalah pada abad 20 dalam konteks propaganda, ekspansi nasional dan penaklukan. Untuk kepentingan riset propaganda, Amerika pada PD I dan II telah membentuk program komunikasi internasional sebagai bidang studi yang resmi di berbagai universitas Amerika Utara. Para sarjana komunikasi antara 1920-an hingga 1950-an banyak berasal dari disiplin ilmu sosiologi, ekonomi dan ilmu politik(McMillin,2007:28). Pada 1926 Harold D. Lasswell mengkaji teknik-teknik perang psikologis bersama Walter Lippman, editor devisi propaganda Amerika. Mereka mempelajari efek teknologi komunikasi terhadap dunia Barat. Hasilnya kemudian, membawa bidang studi komunikasi menjadi bagian dari ilmu sosial. Keduanya - Lippman dan Lasswell - mempromosikan rumus: "who - say what - to whom - with what effect".

Pada 1955 Massachusetts Institute of Technology (MIT), Amerika, telah membuka sebuah program studi, bernama:"Studi Komunikasi Internasional" yang disponsori oleh yayasan perguruan tinggi itu (Allyene,
1997:9). Sejak 1960-an bidang studi ini kemudian dilembagakan di Amerika sebagai salah satu bagian dari bidang studi "Hubungan Internasional". Banyak sarjana komunikasi internasional dididik dengan latar belakang hubungan internasional seperti misalnya, Hamid Maolana. Sementara yang lain berlatarbelakang ilmu sosiologi seperti Everet M. Rogers dan ilmu psikologi seperti Karl Nordenstreng.

Sehabis Perang Dunia II, terjadi Perang Dingin (Cold War) antara Blok Barat yang dipimpin Amerika dengan Blok Timur yang dipimpin Uni Soviet. Perang ini berlangsung dari 1945 hingga 1989 saat tembok Berlin runtuh. Amerika mewakili ideologi kapitalis dan Soviet mewakili ideologi sosialis. Dalam konteks pergulatan komunikasi internasional, Amerika memperjuangkan laissez-faire dan free flow of information yang digagas Komisi Huchin. Belakangan Unesco juga menuntut free flow across border to lead better world yang didukung para peneliti program riset komunikasi internasional (KI) yang tergabung dalam MIT Center for International Studies. MIT ini lalu membentuk Program Riset dalam Komunikasi Internasional yang dipimpin Lasswell, Ithiel de Sola Pool, Karl Dutsch, Daniel Lerner, Schramm, dan Lucian Pye. Riset mereka didanai Ford Foundation.

Keterlibatan Amerika dalam PD II dengan Soviet, membuat para peneliti bias Barat karena strategi KI dirancang agar proBarat dan anti-komunis. Paradigma KI yang menjual doktrin free flow dan the ideal to lead better world kemudian dilegitimasi oleh metoda riset komunikasi yang berpusat pada efek empiris media yang diprakarsai Lasswell, Lazarsfeld dan Hovland. Lahirnya paradigma pembangunan modernisasi yang di dalamnya menempatkan media sebagai magic multiplyer effects pembangunan, telah dijadikan sarana untuk mencapai cita-cita perubahan masyarakat dari tradisonal menuju modern. 
Namun sejalan dengan perkembangan teknologi komunikasi, agensi-agensi kantor berita Barat seperti Reuters atau French Press Agency dan Associated Press (AP) telah mengkonstruksi realitas dunia menurut persepsi Barat. Kala itu, Barat lebih banyak memberitakan berbagai peristiwa negatif negara-negara Dunia Ketiga seperti Amerika Latin, Afrika dan Asia. Mereka digambarkan sebagai negara yang penuh bencana, kudeta, revolusi dan berita-berita negatif lainnya. Di tengah kondisi demikian, datang tawaran pinjaman utang luar negeri, alih teknologi dan resep budaya agar negara-negara Dunia Ketiga mengikuti jalan modernisasi Barat dan sebagian negara Amerika Latin, Afrika dan Asia pun mengikuti jalan tersebut.

Di tengah hiruk-pikuk modernisasi, pada 1960-an diam-diam muncul para sarjana komunikasi Eropa yang tergabung dalam International Association Communication Research (IAMCR). Kelompok ini berasal dari Association for Education in Journalism and mass Communication (AEJMC) yng memiliki tradisi riset kritis. Dengan bantuan Unesco, mereka membentuk Education and Research in International Communication. Dalam riset-riset mereka, ditemukan betapa program-program berita dan hiburan Barat mendominasi media Amerika latin, Afrika dan Asia. Karena itu, mereka melihat adanya imperialisme baru yang bukanlah dilakukan secara hard power melainkan melalui soft power yang disebutnya sebagai imperialisme budaya dan media.

Munculnya mazhab Frankfurt dalam studi komunikasi internasional melalui perspekrtif dependensia dan ekonomi politik misalnya, studi komunikasi internasional telah mengalami "de-westernisasi", meminjam istilah Curran dan Park (2000) sehingga muncul perspektif alternatif pada studi komunikasi internasional dari Eropa dan Asia.

\section{Pengertian K omunikasi Internasional}

Komunikasi internasional, kata Stevenson (1994:543): "It's hard to define, but you know it when you see it". Selain sulit didefinisikan, para ahli komunikasi pun memberi istilah yang saling berbeda tentang komunikasi internasional ini. Ada yang menyebutnya dengan istilah "global communication" (Maulana), "world communication" (Hamelink, 1994), atau "transnational communication" (volkmer). Sementara Kamalipour (2002:xii-xiii) selain menerima istilah di atas, ia menambahkan pula istilah "transborder communication, intercultural communication, cross-cultural communication dan international relations" sebagai padanan lain dari istilah komunikasi internasional". Bagi Kamalipour, semua istilah itu mengandung konsep yang multidimensional dan sangat kompleks. Karena itu, setiap usaha merumuskan definisi yang sederhana pasti hasilnya tidak lengkap dan akan mengundang perdebatan.

Sungguh pun demikian, lanjut Kamalipour, dari sudut makna, lima konsep yang sudah disebutkan di atas saling dapat dipertukarkan, yang semuanya merujuk pada arus informasi yang melintasi batas-batas geografis dari negara-bangsa. Di sisi lain, istilah intercultural copmmunication dan cross cultural communication merujuk pada hubungan antarpersona di antara orang yang memiliki perbedaan latar belakang ras dan budaya. Dan internastional relations (hubungan internasional) fokus utamanya pada kegiatan dan hubungan politik (government-to-government) dan kegiatan dan hubungan ekonomi (bussiness-to-bussiness). Semua istilah itu, sebenarnya punya substansi yang sama. Tetapi, - bila dielaborasi ternyata masing-masing memiliki nuansa, aspek dan lingkup yang berbeda, akibat dari sejarah dan dinamika perubahan teknologi dan hubungan antarbangsa yang dewasa ini tampak semakin kompleks.

Kata "international" didefinisikan Collins English Dictionary (2006:417) 
sebagai: "1) of or involving two or more nations..". Rumusan ini menjelaskan adanya hubungan antarnegara-bangsa satu dengan yang lainnya. Dari defenisi ini, dapat dipahami bila ada yang mengartikan komunikasi internasional oleh McMillin (2007:8) sebagai:'komunikasi yang berlangsung antarbatas persilangan internasional yakni yang melintasi batas-batas negara-bangsa"(Fortner, 1993:6). Sementara McPhail merumuskan komunikasi internasional sebagai "The cultural economical, political, social and technical analysis of communication patterns and effects across and between nationstate" (2000:2).

Dari definisi-definisi itu dapat dilihat bahwa komunikasi internasional lebih berfokus sebagai bagian dari studi hubungan internasional (Mowlana, 1996;1997). Fokus hubungan internasional selama ini berpusat pada interaksi antarnegara dan antarpemerintahan yang dilakukan melalui diplomasi dan aktivitas propaganda yang menempatkan negara yang kuat mendikte agenda komunikasi negara yang lemah. Allyne (1995:7) misalnya, mengaitkan hubungan internasional dengan komunikasi internasional. Bila hubungan internasional diartikan substansial sebagai kekuasaan (power), maka ada tiga kekuasaan yang menonjol dalam dinamika hubungan internasional, yakni: militery power, economic power and power over opinion. Unsur power over opinion inilah yang secara khusus menjadi bahasan dari kajian komunikasi internasional.

Edward Herman dan Robert W.McChesney dalam The Global Media (1997:23) memperkenalkan istilah spesifik, "politik komunikasi internasional"(international communication politic) yang diartikan: "historically refereed relations between nation states, accepting the existing the balance of power as given". Dalam perspektif hubungan internasional, komunikasi internasional dijalankan melalui diplomasi publik (public diplomacy) yang diartikan..,."the way in which both government and private individual and group influence directly or indirectly those public attitudes and opinion which bear directly on other governments' foreign policy decisions(Delaney dalam Arthur S. Hoffman, 1968:3).

\section{Pergeseran dari Internasional ke K omunikasi Global}

Pandangan komunikasi internasional yang berfokus pada interaksi antarnegara, sekarang ini sudah dianggap klasik atau konvensional(). Ditemukannya teknologi informasi dan komunikasi yang baru, interaksi antarindividu dan antarbangsa yang sudah berubah, terutama dalam bisnis dan budaya, telah melahirkan banyak aspek dalam komunikasi internasional. Aktor negara dalam hubungan antarbangsa sekarang ini bukan lagi satu-satunya aktor penting. Dalam era globalisasi dewasa ini, aktor bukan negara (non-state actors) cukup memberi peran yang strategis dan penting. Bahkan ada kalanya lebih penting daripada faktor negara sendiri. Kasus runtuhnya Uni Soviet, runtuhnya tembok Berlin atau jatuhnya Tunisia, Mesir dan Lybia, terjadi hanya gara-gara kegaduhan politik lewat internet.

Akibatnya, terjadilah pergeseran pemahaman dan makna yang memandang komunikasi internasional dalam lingkup yang lebih luas. Philip M. Taylor dalam Global Communications International Affairs and the Media Since 1945 telah memperluas definisi komunikasi internasional sebagai:"...communication between two or more parties (people, governments, organizations) who are located in defferent geographical regions"(1997:22). Ada lagi defenisi yang lebih luas dan umum dari Marks D. Alleyne (1995:21) dalam International Power and International Communication, mendefinisikan komunikasi internasional:..."refers to processes and exchanges in eight areas: tellecomunication; mail; intellectual property; advertising; news; 
movies and TV programmes; books and periodicals and recorded music. Disini Alleyne tidak melihat komunikasi internasional dari sudut aktornya, tetapi dari sudut medium-nya.

Bahkan, Madikiza dan Bornman (2007:17) memperluas komunikasi internasional bukan hanya pada aspek medium-nya, melainkan melihat juga dari sudut efek pesannya. "International communication as a field of study recognises not only the media and technologies throught which impulses pass, but also the attitudes and social circumstances of the sources, the predisposition of recievers, as well as the effect and impact of the contents"(Komunikasi internasional sebagai sebuah bidang studi yang diakui bukan hanya media dan teknologinya saja yang terus berkembang, melainkan juga sikap dan keadaan sosial dari sumber, kecenderungan penerima, baik efek maupun dampak isinya).

Pergeseran fokus komunikasi internasional dari sudut aktor negara ke aktor non-negara, bentuk-bentuk media dan efek pesannya, membuat istilah komunikasi internasional tidak lagi memadai untuk menjelaskan kompleksitas komunikasi internasional dewasa ini. Maka mulailah dikenal istilah "komunikasi global"(global communication) untuk menunjukkan kata Mowlana (1997) bahwa ruang lingkup (scope) dari kajian komunikasi internasional meliputi "komunikasi antarnegara, institusi, kelompok, dan individu lintas batas nasional, geografis dan budaya”. Bahkan Hamelink (1994:2) lebih suka memakai isitlah "komunikasi dunia" (world communication) untuk komunikasi internasional, dengan alasan istilah ini lebih terbuka menjelaskan aktor negara maupun aktor non-negara.

Meskipun komunikasi internasional sudah bermetamorfosis pada komunikasi global atau komunikasi dunia, tetapi secara akademik komunikasi internasional hingga sekarang masih diakui sebagai sebuah subdisiplin dari bidang komunikasi. International Communication Association
(ICA) misalnya, menempatkan komunikasi internasional sebagai salah satu devisi bidang peminatan komunikasi. Demikian juga di berbagai perguruan tinggi Amerika komunikasi internasional telah menjadi kajian utama untuk program doktor dan master. Karena itu, dikenalnya istilah komunikasi global atau dunia komunikasi bukanlah berarti harus menghapus istilah komunikasi internasional. Yang terjadi sebenarnya adalah perluasan ruang lingkup isu dari komunikasi internasional.

Dari beberapa penjelasan di atas dapat disimpulkan bahwa komunikasi internasional terbagi dalam dua pengertian: komunikasi internasional dalam pengertian sempit dan dalam pengertian yang luas. Dalam pengertian yang sempit, komunikasi internasional diartikan sebagai: "proses produksi, distribusi pesan dari satu negara ke negara lainnya". Sedangkan dalam pengertian yang luas, komunikasi internasional diartikan sebagai:"proses produksi dan distribusi pesan yang dilakukan oleh berbagai aktor negara maupun aktor non-negara untuk saling mempengaruhi sehingga tercapai efek yang diharapkan".

Dari perspektif komunikasi, kata Muhammadi (1997):"'international communication is a subfield of communication and media studies where research may be devided according three categories. Pertama, riset komunikasi internasional yang berfokus pada isu budaya dan komodifikasinya. Kedua, riset yang berpusat pada bagaimana informasi didistribusikan oleh konglomerasi media ke seluruh dunia. Ketiga, mengkaji tantangan yang dihadapi oleh negara-negara berkembang dalam pergulatan komunikasi internasional.

\section{Pendekatan K omparatif dan M ultidisiplin}

Ada empat pendekatan terhadap komunikasi internasional, kata Hamied Maulana (1997:6) dalam Global Information and World Order. Pertama, pendekatan 
idealistic-humanistic approach yang menggambarkan komunikasi internasional sebagai sebuah cara membawa bangsa dan negara berdaulat, untuk membantu organisasiorganisasi internasional dalam melaksanakan pelayanannya kepada komunitas dunia lainnya. Bagaimana setiap negara-bangsa mampu menjalin hubungan komunikasi yang harmonis demi mencapai dunia yang damai (world peace). Proses komunikasi seperti ini disebut dengan pndekatan idealistichumanistic.

Kedua, pendekatan yang memandang komunikasi internasional sebagai propaganda, konfrontasi, periklanan, mitos dan klik. Ini disebut juga sebagai "political proselytization". Komunikasi internasional jenis ini lebih bersifat satu arah (one way) yang biasanya dilaksanakan antarinstitusi negara.

Ketiga, berkembangnya pendekatan komunikasi internasional sebagai kekuatan ekonomi (economic power). Hubungan antarnegara ditengarai oleh pertukaran barang dan jasa antarnegara. Mereka sanggup melakukan transfer of technology adalah Negara-negara yang akan berkembang kearah modernisasi atau kemajauan ekonomi "pasar bebas" model neo-liberal.

Keempat, pendekatan komunikasi internasional yang memandang informasi sebagai "kekuasaan politik"(political power). Dominasi informasi: ekonomi, politik, budaya dan teknologi yang datang dari Barat Negaranegara Selatan "terpinggirkan" sehingga terjadi ketergantungan "segala sektor" terhadap Barat.

Empat pendekatan Maolana (1997:67): idealistic-humanistic, procelytization, economic and political", kata Daya KishanThussu (2000:xv) didukung oleh tokohnya masing-masing. Pendekatan idealishumanis yang menggambarkan komunikasi internasional sebagai upaya untuk membangun perdamaian dunia, dipelopori misalnya oleh karya ahli komunikasi asal Inggris Colin Cherry yang berpendapat bahwa komunikasi dapat memajukan dan mempromosikan "harmoni global"(Cherry, 1978).

Sementara pendekatan ekonomi dan implikasi strategis bagi komunikasi internasional, dipelopori oleh Arman Mattelart (1994) dan pendekatan politik atas informasi global dipelopori oleh Cess Hamelink (1995). Dalam pada itu, Tehranian dan Tehranian (1997 dalam McMillin, 2007:9) mengungkapkan empat pendekatan teori komunikasi internasional. Pertama, realism yang memfokuskan diri terutama pada perebutan kekuasaan geopolitik yang mengambil bangsa sebagai pusat analisis. Kedua, liberalism dimana perdagangan bebas dan interdependensi internasional dipandang sebagai jalan yang diperlukan untuk mencapai harmoni global. Ketiga, pendekatan yang menghubungkan Marxisme dan NeoMarxisme dengan menggambarkan konflik kelas antara negara pusat dan pinggiran dari sistem dunia yang dianggap sebagai proses yang terus berlanjut dari era imperialisme, kolonialisme, dan neo kolonialisme. Keempat, pendekatan communitarianism yang berfokus pada pemusatan institusi, budaya, dan komunitas dalam kancah internasional.

Dengan adanya berbagai pendekatan sedemikian itu, maka bidang studi komunikasi internasional membuka cakrawala atas bentuk-bentuk interaksi global yang beragam, termasuk komunikasi global melalui media massa, komunikasi antarbudaya dan kebijakan telekomunikasi. Karena sifatnya yang demikian beragam, komunikasi internasional merupakan bidang studi yang interdisipliner, dengan memanfaatkan konsep, metoda penelitian dan data dari disiplin seperti ilmu politik, sosiologi, ekonomi, budaya, dan sejarah. Isi pesan dalam komunikasi internasional, bukan saja mengandung pesan politik melalui propaganda, diplomasi publik (public diplomacy) dalam konteks hubungan internasional, tapi juga mengandung pesan ekonomi, yang dirancang IMF dan Bank Dunia misalnya, untuk menerapkan ekonomi neo-liberal ke seluruh dunia, atau peran 


\begin{tabular}{lll}
\hline perusahaan-perusahaan & & \\
MNC untuk & mendukung penghormatan kepemilikan \\
menguasai bisnis global. & pribadi. Sedangkan di ujung yang lain, \\
Demikian juga dengan isi pesan budaya, & pandangan demokratis lebih bernuansi politik \\
budaya etnosentrisme Barat dijajagan lewat & $\begin{array}{l}\text { yakni penghormatan atas kebebasan individu } \\
\text { dan kebebasan pers, percaya akan "ruang }\end{array}$ \\
media global sehingga melahirkan & $\begin{array}{l}\text { publik" sebagai tempat perdebatan warga } \\
\text { homogenisasi budaya. Inilah yang }\end{array}$ yang bebas. Dan pada ujung yang lain, \\
menunjukkan bahwa studi komunikasi & pandangan otoritarian yang serba \\
internasional bersifat multidisiplin: & dikendalikan negara. Bila komparasi ini \\
komunikasi, politik, sosiologi, antropologi & mengambil perspektif sistem global, \\
budaya, dan ekonomi. Wataknya yang & sedangkan komparasi empat teori pers lebih \\
demikian, membuat Robert L. Stevenson & menekankan aspek geo-politik. \\
melihat komunikasi internasional sebagai: &
\end{tabular}
theory and one that like other areas of interest, overlaps other disciplines"(Salwen and Stacks, 1996:182-183).

Selain multidisiplin, komunikasi internasional juga berwatak komparatif. Mengapa demikian?. Dalam konteks politik misalnya, operasi media atau komunikasi, ekonomi dan budaya, sangat bergantung pada sistem politik satu negara. Maka sebelum mengkonstruksi tipologi komunikasi, politik atau budaya satu negara, harus lah dilihat terlebih dahulu sistem politknya. "Istilah internasional dalam studi komunikasi internasional", kata Downing, mengandung "makna komparatif" (Wolfgang, 2008:2392) Bidang ini menurut Mark D. Alleyn (2009) dalam Encyclopedia of Communication, mengandung dua dimensi yang luas: (1) policy studies and (2) cultural studies. Studi kebijakan (policy studies) mengacu pada analisis bagaimana tindakan penguasa (seperti pemerintah dan organisasi antarpemerintahan) mempengaruhi sifat dan watak komunikasi internasional. Sedangkan pendekatan kajian budaya (cultural studies) menelaah hubungan antara budaya dengan komunikasi internasional.

Adalah Curran dan Park (2000:11) yang melakukan kajian komparatif media berdasarkan sistem global yang membentangkan ujung kanan neo-liberal dengan ujung kiri regulated. Sedangkan ujung yang lain adalah demokratik dengan authoritarian di ujung yang lain. Pandangan neo-liberal lebih bernuansa ekonomi pasar bebas, anti campur tangan negara dan

\section{Media dan Fungsi Komunikasi Internasional}

Pada dasarnya, media yang digunakan untuk kegiatan komunikasi internasional bersifat konvergen dengan cakupan media konvensional seperti radio, televisi, film, surat kabar dan majalah, maupun media interaktif seperti media online, web, twitter, facebook juga digunakan untuk kegiatan komunikasi internasional. Komunikasi internasional yang bersifat interpersonal, kelompok maupun organisasional pun dilakukan baik oleh aktor negara maupun non negara, termasuk NGO, badan-badan dunia seperti UNESCO misalnya, semuanya dapat secara aktif melakukan kegiatan komunikasi internasional.

Namun, karena karakterisatiknya yang audio visual dan serba hadir di mana-mana (omnipresent), media televisi lebih banyak mendominasi kegiatan komunikasi internasional daripada media-media lainnya. "The big power is TV reporting", kata Philip M. Taylor (2003:85). Alasannya, karena hampir 90 persen warga dunia mendapatkan akses informasi melalui televisi. CNN, Aljazeera, atau MTV misalnya, merupakan medium komunikasi internasional yang dewasa ini sangat dikenal rakyat dunia. Dari sudut struktur industrinya, media yang beroprasi dalam komunikasi internasional dilakukan oleh public broadcasting maupun private broadcasting. Yang satu berorientasi pada kepentingan publik sebagai warga 
negara, sementara yang lain yakni private broadcasting berorientasi pada kepentingan bisnis. Sungguhpun demikian, tidak terlepas dari kepentingan nasional tempat media berada (Fortner, 1993:7).

Adapun fungsi komunikasi internasional, dalam konteks hubungan internasional (international relations), menurut McPhail (2010:87) adalah melakukan diplomasi publik (public diplomation) yang diartikan McPhail sebagai:"effort to inform, influence, and engage global publics in support of national interests". Selanjutnya, McPhail membagi kegiatan diplomasi publik ke dalam dua kategori: tradisional dan modern. Ciri-ciri diplomasi publik tradisional: (1) government to publics; (2) official in nature; (3) necessary evil as technology and new media democratized international relations; (4) linked to foreign policy/national security outcomes; (5) one-way informational and two-way asymetric; (6) give us your best and brightest feature players; (7) passive public role; and (8) crisis driven and reactive. Diplomasi tradisional ini dijalankan saat dunia menghadapi "perang dingin" antara Blok Barat dan Timur.

Pada era "perang dingin", fungsi komunikasi international dari negara-negara Barat, khususnya Amerika bahwa diplomasi publik diarahkan untuk mempromosikan kepentingan penciptaan demokratisasi politik, kebebasan pers melalui "free flow of information" dan sistem ekonomi "pasar bebas" (free-market economy system). Sedangkan diplomasi negara-negara blok Timur yang berorientasi sosialis atau komunis lebih menekankan diplomasi publik atau propaganda pentingnya regulasi negara terhadap semua sistem kehidupan baik ekonomi, politik dan budaya, termasuk regulasi terhadap "kebebasan pers" yang harus tetap dikendalikan negara.

Sedangkan diplomasi publik baru atau modern dijalankan setelah berakhirnya "perang dingin". Pada periode ini, terjadi pemaknaan baru terhadap konsep diplomasi publik, lanjut McPhail. USIA misalnya, mengartikan diplomasi publik sebagai:"seeks to promote the national interest of the U nited States through understanding, informing and influencing foreign audiences". Ciri-ciri diplomasi publik baru (new public diplomacy) adalah:"(1) public to publics; (2) unofficial (NGOs, private citizens, practitioners); (3) everyone doing it; (4) active and participatory public; (5) dialogic and exchange oriented, two-way symetric; (6) generally more long-term; (7) based on relationship, system and network theories.

Meskipun operasi diplomasi publik dewasa ini lebih bersifat dua arah, person to person, dan lebih bersifat kultural daripada politik, mazhab kritis tetap memandangnya sebagai "propaganda" dan "kampanye pemasaran" pihak Barat, mengingat struktur informasi global bersifat timpang (unequal and asymetric) dan tujuan diplomasi publik tidak berubah yakni penyebaran kapitalisme neo-liberal ke seluruh penjuru dunia melalui "information empire" " yang dikuasai Barat. Yang terjadi justru imperialime budaya dan "electronis colonialism".

\section{Daftar Pustaka}

Alleyne, Mark D.(1995). International Power and International Communication. New York: Marten Press.

Curran, James and Park, Myung-Jin (2000). De-Westernizing Media Studies. USA and Canada: Routledge.

Donsbach, Wolfgang, eds (2008). International Encyclopedia of Communication. Mainstreet, Walden: Blackwell Publishing Ltd.

Fortner, Robert S.(1993). International Communication: History, Conflict, and Control of the Global Metropolis. Belmont, California: Wadswort Publishing Company. 
Hamelink, Cees (1995). World Communication. London: Zed Book Ltd.

Herman, Edward and McChesney, R (1997). The Global Media: The Missionaries of Corporate Capitalism. Washington, DC: Cassell.

Hoffman, Arthur S.(1968). International Communication and the New Diplomacy. Bloomington and London: Indiana University Press.

Kamalipour, Yahya R.(2002). Global Communication. International Edition: Wadsworth and Thomson Learning.

Littlejohn, Stephen W., and Foss, Karen A.,eds (2009). Encyclopedia of Communication Theory. Los Angeles, London, New Delhi and Singapore: Sage Reference Publication.

Madikiza, Lucky and Bornman, Elirea (2007). "International Communication: Shifting Paradigms, Theories and Foci of Interest". Communicatio. Volume 33. Unisa Press.

McMillin, Divya C.(2007). International Media Studies. Main Street, Malden: Blackwell Publishing.

McPhail, Thomas L. (2010). Global Communication: Theories,
Stakeholders, and Trends. United Kingdom: Willey-Blackwell.

Mowlana, Hamid (1997). Global Information and World Communication. LondonThousand Oak and New Delhi: Sage Publication.

Muhammadi, Ali, eds (1997). International Communication and Globalization. London, Thousand Oaks and New Delhi: Sage Publication.

Salwen, Michael B., and Stacks, Don W.(1996). An Integrated Approach to Communication Theory and Research. Mahwah, New Jersey: LEA Publishers.

Stevenson, R.L. (1994). Global Communication in the Twenty-First Century. New York: Longman.

Taylor, Philip M.(2003). Global Communications, International Affairs and the Media Since 1945. London and New York: Routledge.

Tehranian, Majid (1999). Global Communication and World Politics: Domination, Development, and Discourse. LSEAS: Lynne Rienner Publishers.

Thussu, Daya Kishan (2007). Media on the Move: Global Flow and Contra-Flow. London and New York: Routledge. 